$\mathbb{T}$ periodica polytechnica

Chemical Engineering

$51 / 1(2007) 710$

doi: $10.3311 / p p . c h .2007-1.02$

web: http://www.pp.bme.hu/ch

(c) Periodica Polytechnica 2007

RESEARCH ARTICLE

\section{Analysis of factors affecting uranium stripping from DEHPA/dodecane using FTIR and other analytical methods}

\author{
Moussa Alibrahim / Habib Shlewit
}

Received 2005-10-19

\begin{abstract}
Uranium(VI) is stripped from 0.1 mol. $\mathrm{l}^{-1}$ DEHPA/dodecane using different concentration of phosphoric acid. This study investigates the main operating variables, mainly phosphoric acid concentration used as a strip solution, and temperature. Infrared spectra of the stripped organic were investigated in region of $P=O$ stretching vibration to represent the effect of the previous variables on uranium stripping and compared with other conventional analytical methods. Results showed that concentration of the strip solution is effective in the range of 5-18 wt\% $\mathrm{P}_{2} \mathrm{O}_{5}$ at fixed temperature, and the temperature effect is less than the strip solution concentration effect by the factor of $1 / 6$. Results obtained enable us to choose the suitable temperature and wt\% $\mathrm{P}_{2} \mathrm{O}_{5}$ of the strip solution to evaluate the demanded stripping distribution ratio.
\end{abstract}

\section{Keywords \\ uranium $\cdot$ infrared $\cdot$ DEHPA $\cdot$ stripping}

\section{Acknowledgement}

The authors like to express their gratefulness to the Director General, Prof. I. Othman, and to Prof. G. Zayzafoon, head of the chemistry Department, for their encouragement and support.

\section{Moussa Alibrahim}

Atomic Energy Commission, Chemistry Department, P.O.Box 6091 Damascus, Syria

e-mail: scientific@aec.org.sy

\section{Habib Shlewit}

Atomic Energy Commission, Chemistry Department, P.O.Box 6091 Damascus, Syria

\section{Introduction}

Surfactants are profitably used in the extraction technology of metal ions from aqueous solutions. Of these, di (2-ethyl hexyl) phosphoric acid, DEHPA constitutes an important surfactant, which can react with positively charged metal ions through its functional group (the head group), $\mathrm{P}=\mathrm{O}$ namely the phosphoryl moiety. In addition to this, it posses long hydrophobic chains, which render the metal complex soluble in the apolar phase (Vandegrift et al [1]).

At a relatively high concentration of DEHPA extractant, the molecules undergo a self-association process. Predominantly, it takes place through a dipole-dipole interaction. This modifies the extraction system, which is manifested in terms of the change in the trend of distribution values. (Das et al [2]).

The infrared spectra of DEHPA showed that the absorption band at $1235 \mathrm{~cm}^{-1}$ was assigned to the $\mathrm{P}=\mathrm{O}$ stretching frequency, where the band at $1665 \mathrm{~cm}^{-1}$ was assigned to the $\mathrm{O}$ $\mathrm{H}$ bending band (Kiwan et al [3]). The infrared spectra of DEHPA in kerosene, show the $\mathrm{P}=\mathrm{O}$ frequency at $1230 \mathrm{~cm}^{-1}$, $\mathrm{O}-\mathrm{H}$ stretching bands at 2680 and $2350 \mathrm{~cm}^{-1}$ were attributed to the formation of dimer and the $\mathrm{O}-\mathrm{H}$ bending band was found at $1690 \mathrm{~cm}^{-1}$. (Sato et al [4]).

The stripping efficiency of uranium from DEHPA can be significantly increased by the use of higher concentration of phosphoric acid in the aqueous strip solution and to ensure that a sufficient fraction of $\mathrm{U}(\mathrm{VI})$ will be transferred into the stripping aqueous solution. The phase ratio aqueous to organic was modified to about 2 at $45-50{ }^{\circ} \mathrm{C}$, (Hurst et al. [5]). Moreover the stripping improvement lies in the use of more concentrated acid, possibly up to $10 \mathrm{~mol} / \mathrm{dm}^{3} \mathrm{H}_{3} \mathrm{PO}_{4}$ instead of $\mathrm{H}_{3} \mathrm{PO}_{4}$ concentration in the range of only 5 to $5.5 \mathrm{~mol} \cdot \mathrm{1}^{-1}$. Hurst et al [6]. A mathematical model was developed to represent the effect of temperature and wt $\% \mathrm{P}_{2} \mathrm{O}_{5}$ on uranium stripping from DEHPA/TOPO. (Dahdouh et al. [7]).

This present work, investigates the intensity variation of $\mathrm{P}=\mathrm{O}$ group in association with $\mathrm{UO}_{2}^{2+}$ ion stretching band (P-O-U) in DEHPA/dodecane, during uranium stripping, using phosphoric acid as a stripping agent and evaluate the optimum temperature and wt $\% \mathrm{P}_{2} \mathrm{O}_{5}$ of the phosphoric acid in order to achieve the 
demanded uranium stripping distribution ratio from the organic phase.

\section{Experimental}

\subsection{Reagents}

Di-(2-ethyl hexyl) phosphoric acid, DEHPA obtained from Sigma with purity $97 \%$. Dodecane with purity $99 \%$ obtained from Merck was used as diluent without further purification. All other reagents were obtained from Merck with Analytical Grade.

\subsection{Procedures}

The solution of $\mathrm{UO}_{2}\left(\mathrm{NO}_{3}\right)_{2}$. 2DEHPA complex which contains $1995 \mathrm{mg} .1^{-1}$ uranium was obtained by shaking $0.1 \mathrm{~mol} . \mathrm{1}^{-1}$ DEHPA in dodecane for 5 hours with appropriate quantities of solid $\mathrm{UO}_{2}\left(\mathrm{NO}_{3}\right)_{2} \cdot 6 \mathrm{H}_{2} \mathrm{O}$ (GR). Solvent layer was separated by centrifugation. Uranium concentration of solvent layer was determined after back extraction by colorimetry using the absorption of $\mathrm{H}_{2} \mathrm{O}_{2}$ complex at $420 \mathrm{~nm}$. Uranium organic solution of $1500 \mathrm{mg} / \mathrm{l}$ and $1000 \mathrm{mg} . \mathrm{l}^{-1}$ were prepared by dilution of the above organic solution.

Three aqueous solutions of pure phosphoric acid 5\% wt $\mathrm{P}_{2} \mathrm{O}_{5}$, $15 \%$ wt $\mathrm{P}_{2} \mathrm{O}_{5}$ and $25 \%$ wt $\mathrm{P}_{2} \mathrm{O}_{5}$, were prepared, and each contained $500 \mathrm{mg} / \mathrm{l}$ uranium to simulate the counter-current process, where the recycled stripping agent loaded by uranium after few stripping stages.

$25 \mathrm{ml}$ of each of the above three aqueous solutions was mixed individually with $25 \mathrm{ml}$ of organic solutions containing $1995 \mathrm{mg} / \mathrm{l}$ uranium, under the following conditions: temperatures: $(20,35,50){ }^{\circ} \mathrm{C}$ and fixed mixing and settling time $10 \mathrm{~min}$ utes to reach the equilibrium. The infrared spectra of the separated and stripped organic phase have been recorded to determine the intensity of P-O-U stretching band.

\subsection{Infrared Measurements}

The infrared spectra were recorded on a Fourier Transform Infrared spectrophotometer (JASCO-300E FTIR) with a resolution of $4 \mathrm{~cm}^{-1}$ using $\mathrm{KBr}$ windows. The cell path length of $\mathrm{KBr}$ windows of the sample and the reference were $0.55 \mathrm{~mm}$.

\section{Results and Discussion}

The $\mathrm{P}=\mathrm{O}$ stretching frequency in DEHPA is observed at 1235 $\mathrm{cm}^{-1}$ by Kiwan et al [3]. The infrared spectra of $0.1 \mathrm{~mol} .1^{-1}$ DEHPA/dodecane solutions containing 1000, 1500, $1995 \mathrm{mg} / \mathrm{l}$ uranium, were recorded, Fig. 1 shows their corresponding infrared spectra, a, b and c respectively. The $\mathrm{P}=\mathrm{O}$ band was shifted from $1235 \mathrm{~cm}^{-1}$ to lower frequency $1197 \mathrm{~cm}^{-1}$, which was assigned to the $\mathrm{P}=\mathrm{O}$ group in association with $\mathrm{UO}_{2}^{2+}$ ions stretching band (P-O-U), and the P-O-U stretching band intensity was strongly decreased when uranium concentration was increased. It's also well considered that the intensity of the band at 940 $\mathrm{cm}^{-1}$ which assigned to the uranyl group in DEHPA was decreased along with the increasing of uranium concentration in

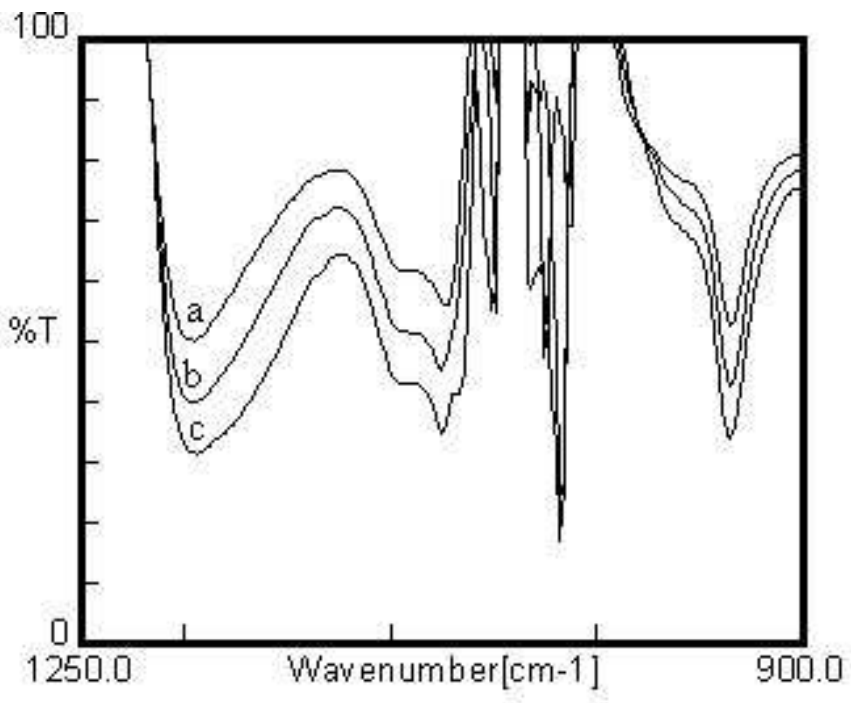

Fig. 1. Infrared spectra of $\mathrm{P}=\mathrm{O}$ band in association with different uranium concentration (a: 1000 , b: $1500, \mathrm{c}: 1995) \mathrm{mg} / \mathrm{l}$ in the organic phase $\left(0.1 \mathrm{~mol} .1^{-1}\right.$ DEHPA/dodecane).

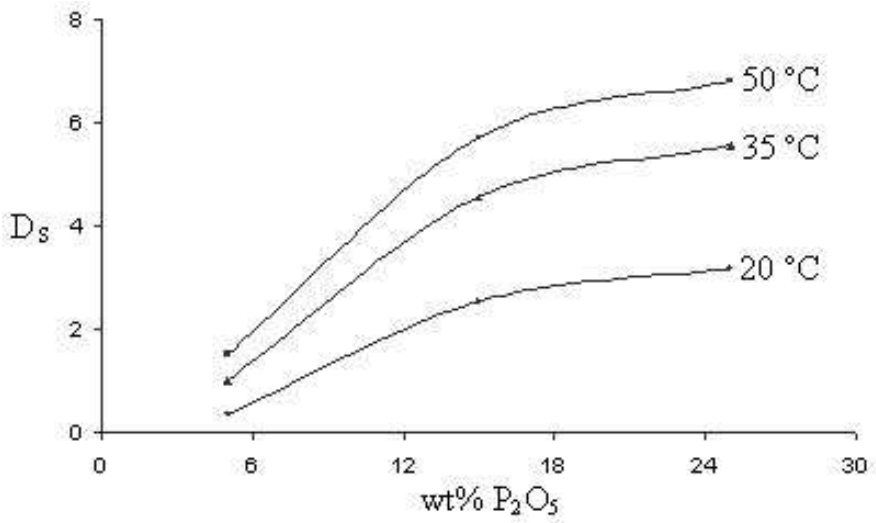

Fig. 2. Uranium stripping distribution ratio $\mathrm{D}_{S}$ as a function of $\mathrm{wt} \% \mathrm{P}_{2} \mathrm{O}_{5}$ at different temperatures.

the aqueous phase (Ohwada et al [8]). Uranium stripping from the organic phase solution of 0.1 mol.1 ${ }^{-1}$ DEHPA/dodecane containing $1995 \mathrm{mg} / \mathrm{l}$ uranium was carried out using aqueous solutions of 5\%wt, $15 \%$ wt and $25 \%$ wt $\mathrm{P}_{2} \mathrm{O}_{5}$, under the above mentioned conditions. The effect of wt $\% \mathrm{P}_{2} \mathrm{O}_{5}$ of the strip solution on uranium stripping distribution ratio $\mathrm{D}_{s}$ at different temperatures is represented in Fig. 2, where, uranium stripping distribution ratio represents the ratio of uranium concentration in the aqueous phase/ uranium concentration in organic phase. Uranium in the stripped organic phase was determined using direct gamma spectrometry of the gamma emission peaks of ${ }^{235} \mathrm{U}$ (Addam and Dams[9]) and UV-VIS spectrophotometer, and in the aqueous phase by mass balance. Results obtained showed that $\mathrm{D}_{s}$ values were agreeing well with the P-O-U band absorption. Fig. 3 shows that the P-O-U stretching band absorption of the stripped organic phase decreased as temperature increased from 20 to $50^{\circ} \mathrm{C}$, therefore uranium stripping distribution ratio also increased. This means that uranium stripping is less efficient at low temperatures. 


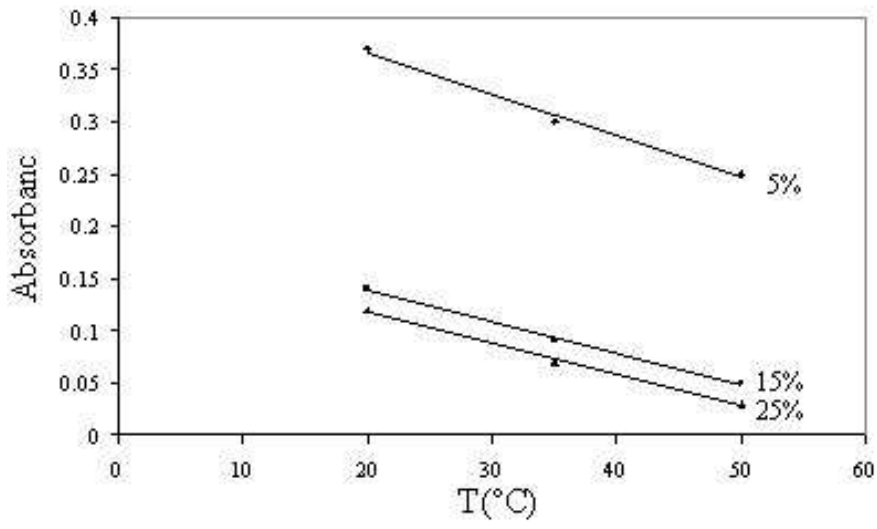

Fig. 3. Absorption of the remained $\mathrm{P}=\mathrm{O}$ stretching band in the association with $\mathrm{UO}_{2}^{2+}$ of the organic phase as a function of temperature, using phosphoric acid containing $5 \% \mathrm{wt}, 15 \%$ wt and $25 \%$ wt $\mathrm{P}_{2} \mathrm{O}_{5}$ as a strip solution.

\subsection{Optimization of Variables Affecting Uranium Stripping}

Plots in Fig. 3 represents the variation of P-O-U band absorption at $1197 \mathrm{~cm}^{-1}$ versus temperature while, wt $\% \mathrm{P}_{2} \mathrm{O}_{5}$ was fixed. Plots of $15 \%$ wt $\mathrm{P}_{2} \mathrm{O}_{5}$ and $25 \%$ wt $\mathrm{P}_{2} \mathrm{O}_{5}$ are closed to each other, and their corresponding $\mathrm{P}-\mathrm{O}-\mathrm{U}$ band absorption values are also close at various temperatures.

In contrary, the P-O-U band absorption plots of 5\%wt $\mathrm{P}_{2} \mathrm{O}_{5}$ and $15 \%$ wt $\mathrm{P}_{2} \mathrm{O}_{5}$ are well separated. It can be concluded that the effect of increasing wt $\% \mathrm{P}_{2} \mathrm{O}_{5}$ on uranium stripping from DEHPA/dodecane-uranyl solution is negligible in the range of about $18-25$ wt $\% \mathrm{P}_{2} \mathrm{O}_{5}$, but the effect is remarkable in the range of 5-18\%wt $\mathrm{P}_{2} \mathrm{O}_{5}$.

The plots of the P-O-U band absorption at $1197 \mathrm{~cm}^{-1}$ versus wt $\% \mathrm{P}_{2} \mathrm{O}_{5}$ at the following temperatures: $20{ }^{\circ} \mathrm{C}, 35^{\circ} \mathrm{C}$ and $50{ }^{\circ} \mathrm{C}$ are represented in Fig. 4. These plots show that, the $\mathrm{P}=\mathrm{O}$ band absorption in association with $\mathrm{UO}_{2}^{2+}$ ions is strongly decreased when wt $\% \mathrm{P}_{2} \mathrm{O}_{5}$ increased from $5 \%$ up to approximately $18 \%$ wt $\mathrm{P}_{2} \mathrm{O}_{5}$, where, $\mathrm{P}-\mathrm{O}-\mathrm{U}$ absorption remains constant as wt $\% \mathrm{P}_{2} \mathrm{O}_{5}$ increased from $18 \%$ to $25 \% \mathrm{wt}$, this means that, using stripping solution of $18 \%$ wt $\mathrm{P}_{2} \mathrm{O}_{5}$ is quite efficient to strip uranium from DEHPA/dodecane-uranyl complex.

P-O-U band absorbance values of 0.2 and 0.15 were selected from Fig. 4 of 0.2 and 0.15 , where, each represents a certain amount of uranium stripping distribution ratio. Temperatures as a function of wt $\% \mathrm{P}_{2} \mathrm{O}_{5}$ were plotted in Fig. 5 forboth of the above selected band absorptions. These plots enable us to choose different temperature and $\mathrm{wt} \% \mathrm{P}_{2} \mathrm{O}_{5}$ values to get the demanded distribution ratio. Moreover, it can be concluded from Fig. 5, that the proportional coefficient of $\Delta w t \% \mathrm{P}_{2} \mathrm{O}_{5} /$ $\Delta \mathrm{T}$ (temperature) is about $1 / 6$, which means that temperature is less effective on uranium stripping distribution ratio if compared with the wt $\% \mathrm{P}_{2} \mathrm{O}_{5}$ effect by the factor of $1 / 6$, which is from the economical point of view a valuable result.

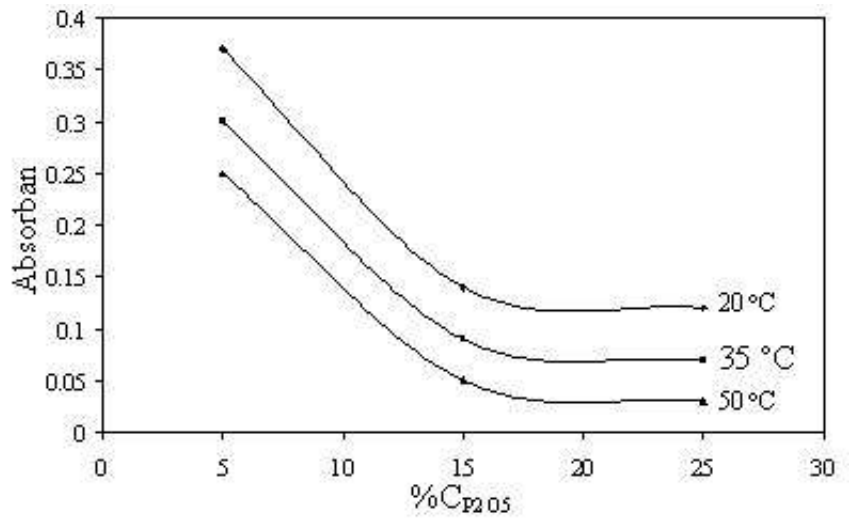

Fig. 4. Absorption of the remained $\mathrm{P}=\mathrm{O}$ stretching band in the association with $\mathrm{UO}_{2}^{2+}$ of the organic phase as a function of wt $\% \mathrm{P}_{2} \mathrm{O}_{5}$ at $20^{\circ} \mathrm{C}, 35^{\circ} \mathrm{C}$ and $50^{\circ} \mathrm{C}$.

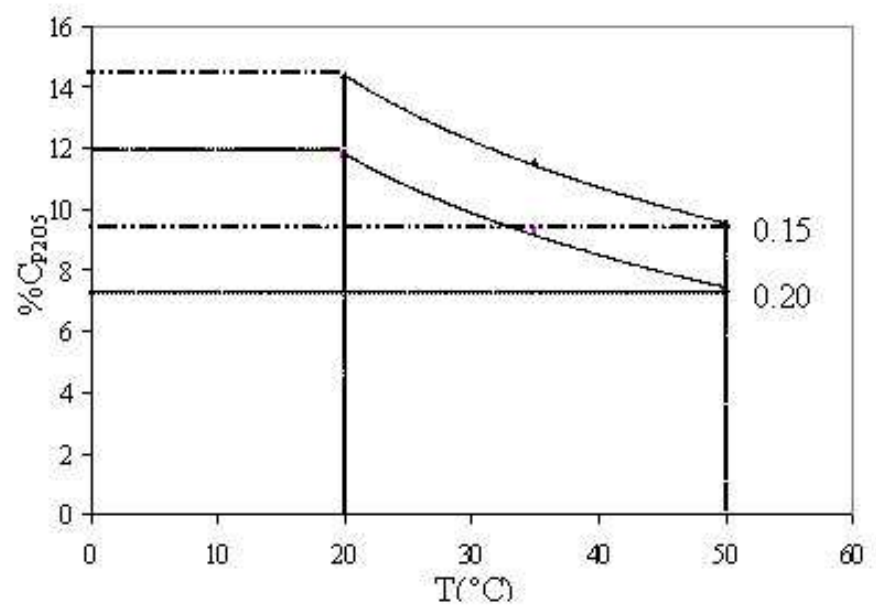

Fig. 5. wt $\% \mathrm{P}_{2} \mathrm{O}_{5}$ of the stripping agent at the selected band absorption of 0.15 and 0.20 as a function of temperature.

\section{Conclusion}

It can be concluded from the recorded infrared spectra of the DEHPA-uranyl complex in dodecane that uranium stripping was increased, when wt $\% \mathrm{P}_{2} \mathrm{O}_{5}$ of the stripping agent and temperature increased from $5 \%$ to $18 \%$, and from $20^{\circ} \mathrm{C}$ to $50{ }^{\circ} \mathrm{C}$, respectively. Temperature influence on uranium stripping is less by the factor of $1 / 6$ if compared with that of the wt $\% \mathrm{P}_{2} \mathrm{O}_{5}$ of the stripping agent. The influence order of temperature and wt $\%$ $\mathrm{P}_{2} \mathrm{O}_{5}$ on uranium stripping is agreeing well with results obtained by (Dahdouh et al [7]).

Results obtained enable us to select the suitable temperature and wt $\% \mathrm{P}_{2} \mathrm{O}_{5}$ of the stripping agent to evaluate the demanded uranium stripping distribution ratio. 


\section{References}

1 Vandegrift GF, Horwitz EP, Interfacial Activity of Liquid-Liquid Extraction Reagent-I: Dialkyl phosphorous based acids, J. Inorg. Nucl. Chem. 42 (1980), no. 1, 119-125.

2 Das NR, Nandi B, Bhattacharya SN, Separation of Molybdenum from Tungsten with Di(2-ethyl hexyl) Phosphoric Acid as Extractant, Anal. Chim. Acta. 159 (1984), 255.

3 Kiwan AM, Amin RS, Extraction of uranium(IV) by di-2-ethylhexylphosphoric acid from perochloric acid solutions, J. Inorg. Nucl. Chem. 33 (1971), no. 7, 2221-2228.

4 Sato T, Nakamura T, Kawamura M, The Extraction of Vanadium(IV) from Hydrochloric Acid Solutions by DEHPA, J. Inorg. Nucl. Chem. 40 (1978), 853-856.

5 Hurst FJ, Crouse DJ, Brown KB, Recovery of uranium from wet-process phosphoric acid, Ind. Eng. Chem. Process Des. Dev. 11 (1972), no. 1, 122128.

6 Hurst FJ, Crouse DJ, Equilibrium and kinetic studies of the reductive stripping of uranium from DEPA-TOPO reagent into aqueous phosphoric acid, Hydrometallurgy 13 (1984), 15-32.

7 Dahdouh A, Shlewit H, Khorfan S, Kodsi Y, Study of Factors Affecting Uranium Stripping from DEHPA/TOPO Solvent by Factorial Design, J. Radio Anal. \& Nucl. Chem. 221 (1997), no. 1-2.

8 Ohwada $\mathbf{K}$, Ishihara T, Infra-red spectrophotometry of uranyl nitrate/tri-nbutyl phosphate in organic solvents, J. Inorg. Nucl. Chem. 28 (1966), 23432345.

9 Addams F, Dams R, Applied Gamma Ray Spectrometry, International Ser. Anal. Chem. 41 (1970). 